\title{
Outbreak
}

\section{Tuberculosis outbreak among high school students in Novi Pazar, Serbia 2016: a retrospective-cohort study}

\author{
Maja Stosic ${ }^{1 *}$, Dragana Plavsa ${ }^{2}$, Nikoletta Mavroeidi ${ }^{3}$ Dragana Jovanovic ${ }^{4}$, Violeta Mihailovic Vucinic ${ }^{4}$, \\ Goran Stevanovic ${ }^{5}$, Lidija Sagic ${ }^{6}$, Sefadil Spahic ${ }^{7}$, Uros Rakic ${ }^{2}$, Anita Grgurevic ${ }^{8}$ \\ ${ }^{1}$ Department of HIV, hepatitis, STDs and TB, Public Health Institute of Serbia "Dr Milan Jovanovic Batut", Belgrade, \\ Serbia \\ ${ }^{2}$ Department of Epidemiological Surveillance, Public Health Institute of Serbia "Dr Milan Jovanovic Batut", \\ Belgrade, Serbia \\ ${ }^{3}$ Child and Adolescent Centre, Athens, Greece \\ ${ }^{4}$ University Hospital of Pulmonology, Clinical Center of Serbia, Belgrade, Serbia \\ ${ }^{5}$ Clinic for Infectious and Tropical Diseases, Clinical Center of Serbia, Belgrade, Serbia \\ ${ }^{6}$ Municipality Institute for Tuberculosis and Lung Diseases, Belgrade, Serbia \\ ${ }^{7}$ District Public Health Institute, Novi Pazar, Serbia \\ ${ }^{8}$ Institute of Epidemiology, Faculty of Medicine, University of Belgrade, Belgrade, Serbia \\ * Authors contributed equally to this work.
}

\begin{abstract}
Introduction: Between February and November 2016, 17 tuberculosis (TB) cases were identified among high school students in Novi Pazar, Serbia. The objectives of our study were to describe the outbreak, to identify potential risk factors and to evaluate the applied control measures. Methodology: The outbreak was described by time, person and place. A retrospective cohort study was conducted. Attack rates, unadjusted relative risks (RR) and 95\% confidence intervals (CI) were calculated. Multiple log-binomial regression analysis was performed to calculate adjusted RR.

Results: Sixteen of the total 17 cases occurred among grade 3 students, AR 5.5\%. Previous TB family history, $(\mathrm{RR}=5.29 ; 95 \%$ CI $=1.63$ 17.12), spending time with a known $\mathrm{TB}$ case at school $(\mathrm{RR}=5.38 ; 95 \% \mathrm{CI}=1.48-19.55)$ and exposure to secondhand $\mathrm{smoke}(\mathrm{RR}=3.37 ; 95 \%$ $\mathrm{CI}=1.11-10.29)$ were all significantly and independently associated with the occurrence of TB.

Conclusions: Delayed diagnosis and reporting resulted in delayed initiation of the contact investigation and non-identification of latent TB cases probably favored the occurrence of this outbreak in a low incidence country. Public health authorities should consider revising the existing guidelines, promoting inter-sectorial collaboration and increasing awareness of public health professionals.
\end{abstract}

Key words: tuberculosis; outbreak; retrospective cohort study; high school; Serbia.

J Infect Dev Ctries 2019; 13(2):101-110. doi:10.3855/jidc.10952

(Received 15 October 2018 - Accepted 22 december 2018)

Copyright $(C 2019$ Stosic et al. This is an open-access article distributed under the Creative Commons Attribution License, which permits unrestricted use, distribution, and reproduction in any medium, provided the original work is properly cited.

\section{Introduction}

Tuberculosis (TB) disease results from infection with the pathogen Mycobacterium tuberculosis and spreads by respiratory transmission. It is predominantly a disease of the lungs, with pulmonary TB accounting for $70 \%$ of cases, however $M$. tuberculosis can spread to other organs leading to extra-pulmonary disease. Although 10 million new cases of active TB are still reported annually, the majority of infected individuals do not develop an active form of the disease [1]. It is estimated that up to one-fourth of the world's population is infected with $M$. tuberculosis but are asymptomatic and therefore defined as having latent TB
[2]. Majority of these individuals will control this latent infection, but only 5 to $10 \%$ will develop TB during their lifetime [3].

The incidence of tuberculosis (TB) has decreased over the last 10 years in Serbia, from 37 per 100,000 in 2003 to 12 per 100,000 in 2016 [4] making it a low TB incidence country [5]. The treatment success rates for drug-susceptible TB were satisfactory until 2011 when the rate was $87 \%$. However, it decreased from $85 \%$ in 2012 to $75 \%$ in 2015 [4]. Large differences in incidence were observed among districts: the lowest rates were recorded in the north while the highest recorded in south-west parts of the country [4]. According to the 
national immunization schedule, BCG (Bacille Calmette Guérin) vaccine is mandatory and administered to newborn children as a single dose [6]. According to the national guidelines, [7] investigation of all contacts older than 14 years is performed by chest $\mathrm{x}$-ray. The use of tuberculin skin testing (TST) or Interferon Gamma Release Assays (IGRA) for the detection of latent TB-LTB is currently not recommended [7].

The City of Novi Pazar (2016 population: 104,674) is located in the south-west of the country [8]. TB notification rates in Novi Pazar do not follow the declining trend. Over the last ten years, it has been the city with the highest TB notification rate in Serbia, 3139 per 100,000, 2-3 times higher than the country's average. Coverage of BCG vaccination in Novi Pazar was $96-100 \%$ over the last twenty years corresponding with the data for the rest of the country [4].

\section{Outbreak description}

According to the national guidelines, the $\mathrm{TB}$ outbreak is defined as an increase in the number of TB cases in time and place above the expected rate [7]. Between February and May 2016, 4 TB cases had been reported among high school students in Novi Pazar (40 classes, 1194 students and 99 employees). No TB cases had been reported among students in other schools.

Local and national health authorities conducted active case finding among students between June and September 2016 among 1003 students (84\% of the total) and 99 employees (100\%) reporting at least one symptom of the following: cough, hemoptysis, fever, night sweats, weight loss, chest pain, shortness of breath, fatigue using fluorography on the field [9]. Those with positive fluorography were further screened by chest radiography and referred for sputum analysis (microscopy and culture). A computed tomography (CT) scan was performed in cases of inconclusive radiography findings. In suspected extra-pulmonary TB cases, microbiological examination of another appropriate sample was performed including surgical biopsy [9].

Eleven new active TB cases were identified among third-grade high school students. The second round of active case finding was performed in October 2016 among the remaining 292 high school students. By the end of November 2016, six additional TB cases were identified; five in the third grade and one case in the second grade, making a total of 17 cases. No cases were identified among employees. It is well known that the proximity of students in the classrooms, as well as crowded living conditions may facilitate TB transmission [10,11]. However, little is understood about the transmission dynamics and risk factors in an outbreak setting and the evidence of TB outbreak investigation in Serbia so far has been scarce [12].

The objectives of the study were to describe the outbreak among high school students in Novi Pazar, Serbia and to identify risk factors for TB during this outbreak among third grade high school students in order to evaluate the control measures and prevent future outbreaks.

\section{Methodology}

We reviewed the medical records of the cases and reports by the District health authorities to describe the outbreak by time, person and place. Descriptive analysis was conducted continuously during the outbreak among the high school students population (n $=1194$ ), while retrospective cohort study was performed in December 2016 among third-grade high school students $(n=292)$. Outbreak cases included seventeen TB patients among high school students over a 1-year observation period after the initial contact. Retrospective cohort analysis included sixteen cases. Case definition and classification was performed in line with the latest European Commission Implementing Decision:

- Possible TB case was defined as any person meeting the clinical criteria (signs, symptoms and/or radiological findings consistent with active TB in any site and a clinician's decision to treat the person with a full course of anti-tuberculosis therapy).

- Probable case as any person meeting the clinical and laboratory criteria for a probable case.

$\checkmark$ Laboratory criteria for a probable case. At least one of the following three:

$\checkmark$ Microscopy for acid-fast bacilli or equivalent fluorescent staining bacilli on light microscopy

$\checkmark$ Detection of Mycobacterium tuberculosis complex nucleic acid in a clinical specimen

$\checkmark$ Histological appearance of granuloma.

- Confirmed case was defined as any person meeting the clinical and the laboratory criteria for case confirmation.

$\checkmark$ Laboratory criteria for case confirmation. At least one of the following two:

$\checkmark$ Isolation of Mycobacterium tuberculosis complex (excluding Mycobacterium bovisBCG) from a clinical specimen

$\checkmark$ Detection of Mycobacterium tuberculosis complex nucleic acid in a clinical specimen 
AND positive microscopy for acid-fast bacilli or equivalent fluorescent staining bacilli on light microscopy [13].

Clinical characteristics and information on microbiological diagnosis were recorded for all cases.

Laboratory confirmation was performed at the National Reference Laboratory for mycobacteria by detection of the presence of $M$. tuberculosis and drug susceptibility testing to rifampicin and isoniazid using molecular techniques, cultivation in liquid media with different sensitive systems for early detection of the growth and rapid identification of isolated cultures using immune-chromatographic assays and molecular techniques. Genetic cluster was detected using the Mycobacterium tuberculosis-specific multiple locus VNTR (Variable Number of Tandem Repeats) analysis (MLVA) on the 11 isolates. Mycobacterial interspersed repetitive units (MIRU) genotyping was performed in Supranational Reference Laboratory for mycobacteria in Borstel, Germany

A retrospective cohort study was conducted among the third-year high school students to examine the risk
Figure 1. Epidemiological linkage between the outbreak cases. Red circles represent sputum smear positive cases; yellow circles represent culture positive cases; blue circles represent extra pulmonary cases.

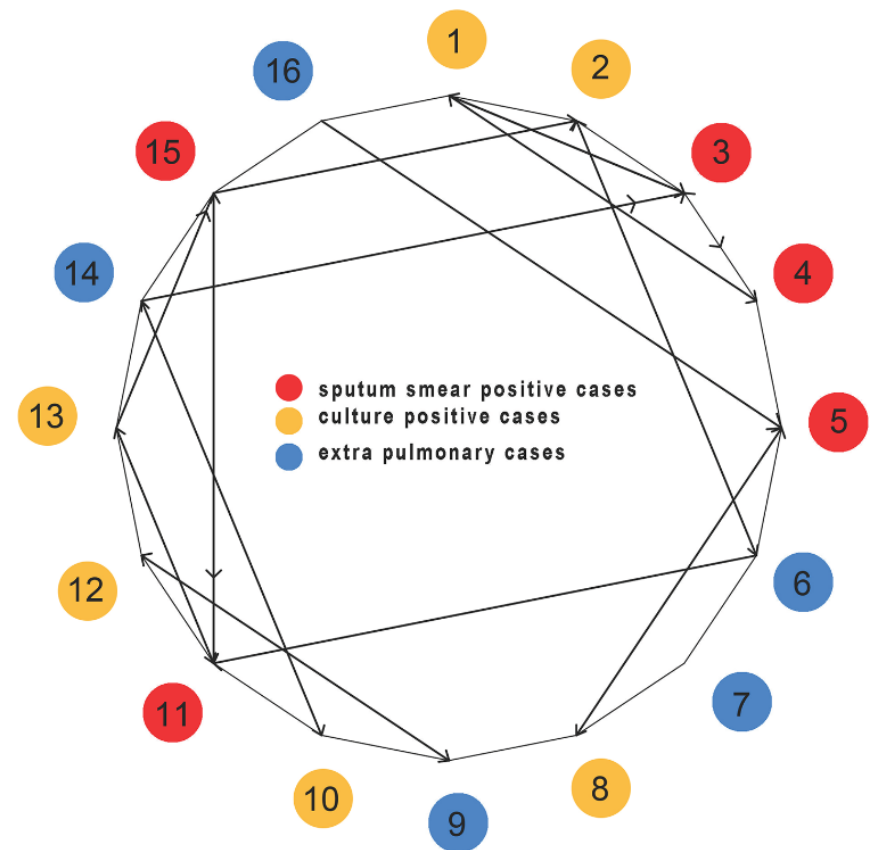

Figure 2. Geographic distribution of the outbreak cases. The green symbol represents a position of a high school; the yellow symbols indicate the places of living of the cases in Novi Pazar in relation to the position of high school. (Image courtesy of Google Maps).

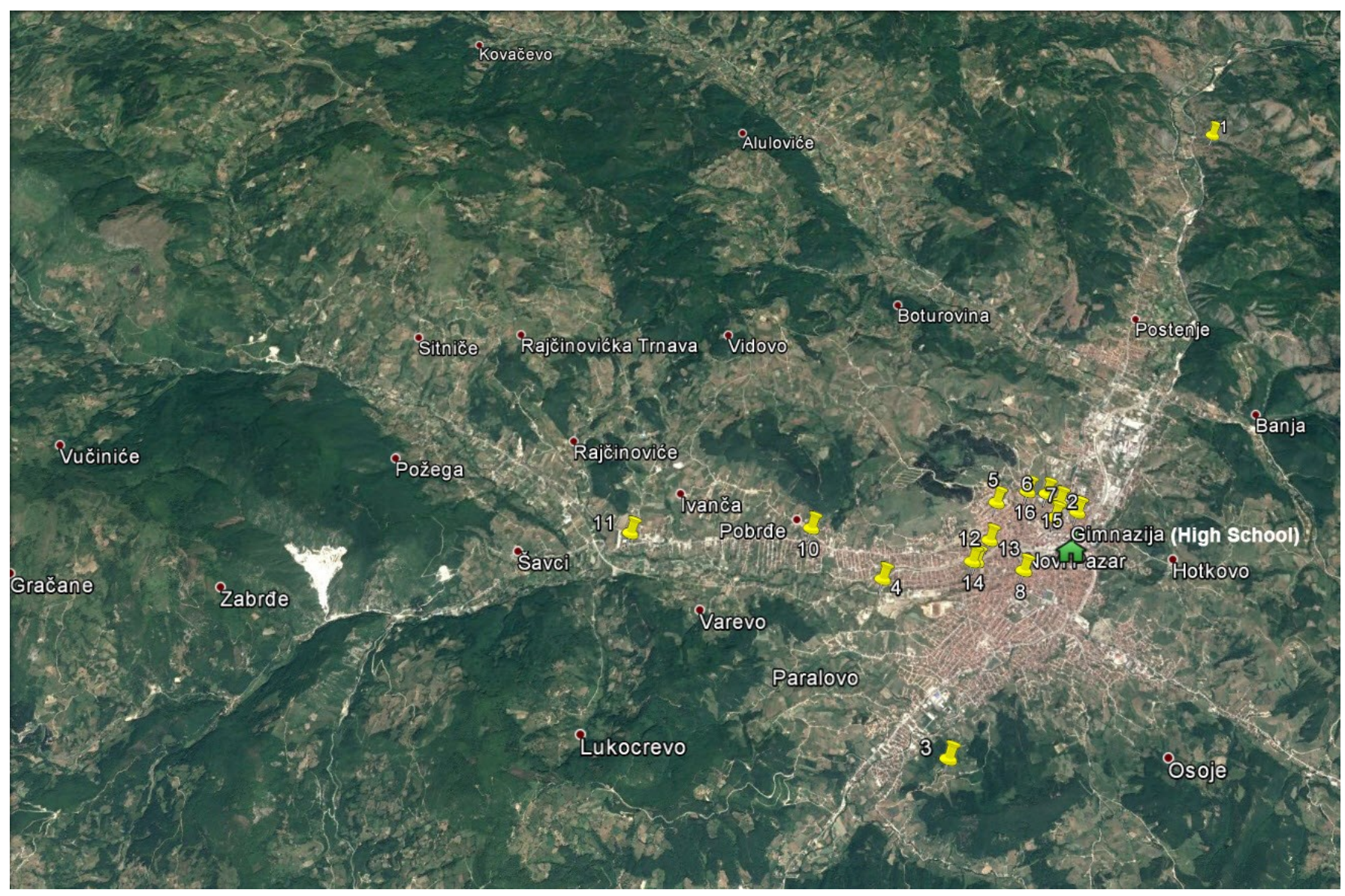


of disease among high school students exposed and unexposed to various risk factors. The study instrument included six groups of exposure variables : demographics and socio-economic factors: gender, age, height, weight, residence, family size, household income; health behavior: regular daily food intake (three meals per day), regular daily sleeping pattern ( 8 hours), current smoking status, exposure to secondhand smoking, current use of hookah, sharing hookah, current alcohol consumption, experience of stressful situations in the past 24 months ; known exposure to TB inside and outside the school: time spent at school during classes per day, time spent at school during school breaks per day, spending school breaks outside the school, history of TB in the family and among friends, spending $\geq 8$ hours per week with a known TB case at school-"TB friend"; immunosuppression and comorbidities: cancer, gastrectomy, jejuno-ileal bypass, silicosis, renal insufficiency, diabetes, malnutrition, asthma or other. After a pilot study among ten students, face to face interviews were conducted by the local health staff previously trained on the interview methodology.

\section{Statistical analysis}

Descriptive statistics was used to obtain summary values and attack rates (AR). Unadjusted relative risks (RR) and 95\% confidence intervals (CI) for all exposure variables were calculated in univariate analysis. Multiple log-binomial regression analysis was performed to calculate adjusted RR. The outcome variable was TB disease. Statistically significant variables in univariate analysis were included in the multivariable model. The variable "TB history among friends", although statistically significant, was not included in the model. This variable referred to the "friends" at school, thus, overlapping with the exposure "spending time with TB friends" at school, the latter was ultimately considered more relevant as it also included the duration of the exposure.

Statistical significance was set at $p<0.05$. Data were analyzed using Statistical Package for Social Sciences (IBM SPSS) version 24.

\section{Results}

Descriptive analysis

Overall, 17 cases were detected from February to November 2016 among the 1,194 students (AR 1.42 $\%$ ), one case was identified in grade 2 (AR $0.33 \%$ ) and 16 cases in grade 3 (AR 5.5\%). No cases were detected among grade 1 and grade 4 high school students.
Among 17 TB cases, 11 (64.7\%) were confirmed cases, $1(5.8 \%)$ was a probable case and $5(29.4 \%)$ were possible TB cases. Overall, pulmonary (11) and extrapulmonary (6) forms accounted for $64.7 \%$ and $35.2 \%$ of the total cases, respectively. Whereas, 7 of the pulmonary TB cases were sputum smear positive, $63.6 \%$ or $41 \%$ of the total.

Almost all cases (94.1\%) were epidemiologically connected (Figure 1). No link was not observed between the first and the last case. Each case was linked consecutively with the next except cases 4 and 5 and cases 8 and 9. Cases 5 and 9 attended classes where the TB cases were already reported. Case number 7 did not report a connection with any of the TB cases from this outbreak. Geographic distribution of all cases is presented in Figure 2.

A total of 16 third-grade high school students developed TB during this outbreak. The third-grade high school population consisted of 292 students distributed in 10 classes. Cases were identified in 8 classes. The highest AR by classroom was observed in classrooms (C) number $10(11.5 \%)$ and $3(10.0 \%)$ respectively, while the lowest AR was found in classrooms number $2(4.5 \%)$ and $8(6.1 \%)$. The mean age of the third-grade students was $18.19 \pm 0.40$. Gender specific AR for females and males were $9.0 \%$ and $6.6 \%$, respectively. The pulmonary (11) and extra-pulmonary (5) form of the disease accounted for $68.7 \%$ and $31.3 \%$ respectively, whereas 5 of the pulmonary TB cases were sputum smear positive ( $45.4 \%$ of the pulmonary cases and $31.3 \%$ of the total).

The median time between the onset of symptoms and seeking medical assistance was 5 days (0-30). The time lag between the date of onset and the date of diagnosis was 13.7 days.

Figure 3. Distributions of cases by date of symptom onset and date of notification.

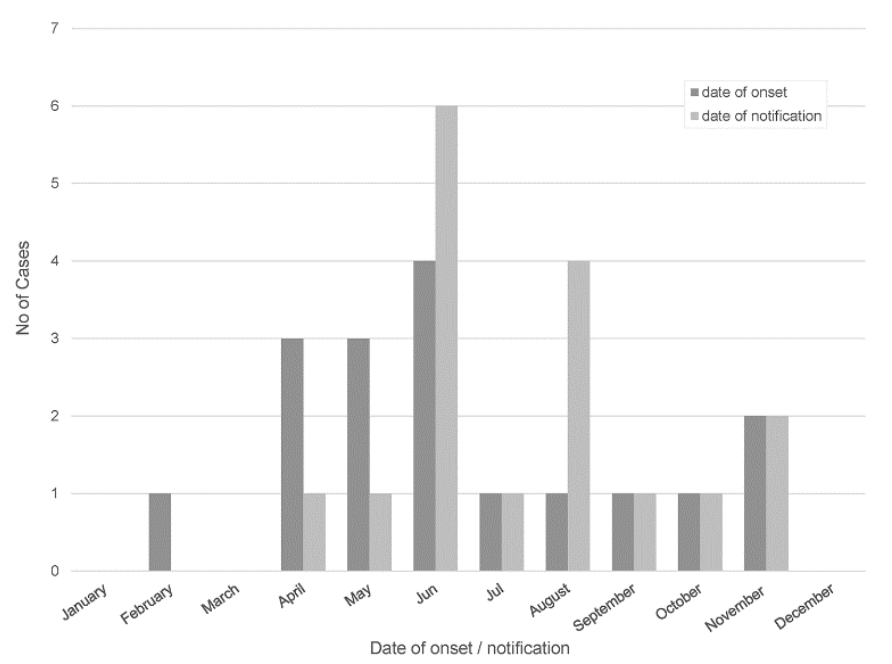


Table 1. Attack rates and factors related to TB according to the univariate regression analysis.

\begin{tabular}{|c|c|c|c|c|c|}
\hline Variables & $\begin{array}{c}\text { TB cases } \\
\text { n }(16)\end{array}$ & $\begin{array}{c}\text { Total } \\
\text { N (202) }\end{array}$ & $\begin{array}{l}\text { Attack rate } \\
(\%)\end{array}$ & RR $(95 \%$ CI $)$ & p value \\
\hline \multicolumn{6}{|l|}{ Gender } \\
\hline Female & 10 & 111 & 9.0 & \multirow[t]{2}{*}{$1.36(0.49-3.76)$} & \multirow[t]{2}{*}{0.546} \\
\hline Male & 6 & 91 & 6.6 & & \\
\hline \multicolumn{6}{|l|}{ BMI } \\
\hline$\leq 19$ & 2 & 28 & 7.1 & \multirow{2}{*}{$0.87(0.26-5.07)$} & \multirow[t]{2}{*}{0.848} \\
\hline$>19$ & 14 & 170 & 8.2 & & \\
\hline \multicolumn{6}{|l|}{ Residence } \\
\hline Rural & 11 & 120 & 9.2 & \multirow{2}{*}{$1.50(0.52-4.33)$} & \multirow{2}{*}{0.450} \\
\hline Urban & 5 & 82 & 6.1 & & \\
\hline \multicolumn{6}{|l|}{ Family size } \\
\hline$>5$ & 9 & 85 & 10.6 & \multirow{2}{*}{$1.75(0.65-4.71)$} & \multirow[t]{2}{*}{0.265} \\
\hline$\leq 5$ & 7 & 116 & 6.0 & & \\
\hline \multicolumn{6}{|c|}{ Monthly income of the Family (Euro) } \\
\hline$\leq 500$ & 11 & 108 & 10.2 & \multirow{2}{*}{$2.14(0.68-6.71)$} & \multirow[t]{2}{*}{0.193} \\
\hline$>500$ & 5 & 84 & 4.8 & & \\
\hline \multicolumn{6}{|l|}{ Current smoker } \\
\hline Yes & 2 & 47 & 4.3 & \multirow[b]{2}{*}{$0.47(0.11-2.07)$} & 0.319 \\
\hline No & 14 & 155 & 9.0 & & \\
\hline Current hookah us & & & & & \\
\hline Yes & 3 & 66 & 4.5 & & 0.246 \\
\hline No & 13 & 136 & 9.6 & 0.48 (0.14-1.67) & \\
\hline Sharing hookah & & & & & \\
\hline Yes & 2 & 47 & 4.3 & & 0.754 \\
\hline No & 1 & 16 & 6.3 & $0.68(0.06-7.51)$ & \\
\hline Alcohol consumpti & & & & & \\
\hline Yes & 3 & 57 & 5.2 & & 0.406 \\
\hline No & 13 & 145 & 9.0 & $0.59(0.17-2.06)$ & \\
\hline Regularly daily slee & & & & & \\
\hline$\geq 8$ hours & 2 & 31 & 6.5 & & 0.753 \\
\hline$<8$ hours & 14 & 171 & 8.2 & $0.79(0.18-3.47)$ & \\
\hline Regularly daily eat & & & & & \\
\hline$\geq 3$ meals per day & 7 & 87 & 8.1 & & 0.954 \\
\hline$<3$ meals per day & 9 & 115 & 7.8 & $1.03(0.38-2.76)$ & \\
\hline Exposure to second & & & & & \\
\hline Yes & 9 & 65 & 13.8 & & 0.048 \\
\hline No & 7 & 137 & 5.1 & $2.71(1.01-7.28)$ & \\
\hline $\begin{array}{l}\text { Did something tro } \\
\text { months? }\end{array}$ & & & & & \\
\hline Yes & 7 & 79 & 8.1 & & 0.952 \\
\hline No & 9 & 105 & 7.9 & $1.03(0.38-2.77)$ & \\
\hline Co-morbidities & & & & & \\
\hline Yes & 2 & 7 & 28.6 & $308(000-1751)$ & 0.068 \\
\hline No & 14 & 195 & 7.2 & $3.98(0.90-17.51)$ & \\
\hline Spending time in sc & & & & & \\
\hline$\geq 5$ hours per day & 9 & 74 & 12.2 & & 0.113 \\
\hline$<5$ hours per day & 7 & 128 & 5.5 & $2.22(0.83-5.97)$ & \\
\hline Spending time duri & & & & & \\
\hline In school & 12 & 93 & 12.9 & & 0.029 \\
\hline Out of school & 4 & 109 & 3.7 & $3.52(1.13-10.90)$ & \\
\hline Previous TB diseas & & & & & \\
\hline Yes & 4 & 7 & 57.1 & $9.28(2.99-28.79)$ & 0.001 \\
\hline No & 12 & 195 & 6.1 & & \\
\hline TB disease among & & & & & \\
\hline Yes & 14 & 124 & 11.3 & & 0.049 \\
\hline No & 2 & 78 & 2.6 & $4.40(1.01-19.37)$ & \\
\hline Spending time with & & & & & \\
\hline$\geq 8$ hours per week & 11 & 45 & 24.4 & & \\
\hline$<8$ hours per week & 3 & 76 & 3.9 & $6.19(1.73-22.20)$ & 0.005 \\
\hline
\end{tabular}


The median time between onset of symptoms and reporting of the cases to the district health authorities was 21 days $(0-82)$. The median time between the diagnosis and reporting was 2 days $(0-60)$, it was longer than 24 hours in 11 cases $(68.7 \%)$ and $34.7 \pm 25$ days for the first four cases. Distributions of cases by date of symptom onset and date of notification are presented in Figure 3.

\section{Risk factors analysis}

Risk factors analysis included 202 out of 263 students present at the school at the time of the study, making the response rate of $76.8 \%$. AR and factors related to TB are presented in Table 1. Students with family size exceeding 5 members had a higher AR $(10.6 \%)$ compared with students with a family size less than or equal 5 members $(6.0 \%)$. But the observed difference was not statistically significant $(R R=1.75$; $95 \% \mathrm{CI}=0.65-4.71)$. Similar findings were noticed for students living in a rural and urban setting with AR $9.2 \%$ and $6.1 \%$, respectively. Students with an estimated monthly income less than 500 Euro per family had higher AR (10.2\%) than students with an estimated monthly income more than 500 Euro (4.8\%). However, the observed RR was not statistically significant $(p=0.193)$. Table 1 lists other nonsignificant RRs including body mass index (BMI), current smoking status, alcohol consumption, using hookah, sharing a hookah, regular daily food intake, regular daily sleeping pattern, the experience of stressful situations and co-morbidities. Dominant comorbidities among TB patients were recurrent bronchitis and asthma.

Students exposed to secondhand smoking had 2.7 times higher risk of developing TB compared to students who were not exposed to secondhand smoking $(\mathrm{RR}=2.71 ; 95 \%$ CI 1.01-7.28). Students who spent at least 5 hours per day in the school during classes had 2.2 times higher risk of developing TB than those who spent less than 5 hours per day $(\mathrm{RR}=2.22 ; 95 \% \mathrm{CI}=$ $0.83-5.97)$. Spending time in school during school breaks have been found to have RR of 3.52 (95\% CI = 1.13-10.90). In addition, there was a significant difference in AR between the groups of students who spent more than vs less than eight hours per week with
TB friend in school $(\mathrm{RR}=6.19 ; 95 \% \mathrm{CI}=1.73-22.20)$. Those who spent at least eight hours per week with TB friend had 6 times higher risk of developing TB compared to those who spent less than 8 hours per week. Also, previous $\mathrm{TB}$ disease in the family $(\mathrm{RR}=$ 9.28; $95 \% \mathrm{CI}=2.99-28.79)$ and among friends ( $\mathrm{RR}=$ $4.40 ; 95 \% \mathrm{CI}=1.01-19.37)$ was significantly associated with developing TB.

In multivariable log-binomial regression analysis (Table 2), three variables were found to be significant independent risk factors for the development of $\mathrm{TB}$ among high school students: previous TB disease in family $(\mathrm{RR}=5.29 ; 95 \% \mathrm{CI}=1.63-17.12)$, spending time with TB friend in the school $(\mathrm{RR}=5.38 ; 95 \% \mathrm{CI}$ $=1.48-19.55)$ and exposure to passive smoking $(\mathrm{RR}=$ 3.37 ; $95 \% \mathrm{CI}=1.11-10.29)$.

\section{Laboratory investigation}

All culture-positive cases (11) were drugsusceptible strains. Genotyping confirmed the presence of the genotype cluster.

\section{Discussion}

This is the first TB outbreak among high school students in Serbia investigated by analytical methods. Three variables were found to be independently associated with the occurrence of TB among high school students: previous $\mathrm{TB}$ disease in family $(\mathrm{RR}=$ $5.29 ; 95 \% \mathrm{CI}=1.63-17.12)$, spending time with $\mathrm{TB}$ friend in school $(\mathrm{RR}=5.38 ; 95 \% \mathrm{CI}=1.48-19.55)$ and exposure to secondhand smoking $(\mathrm{RR}=3.37 ; 95 \% \mathrm{CI}$ $=1.11-10.29)$. The percentage of confirmed cases in this outbreak was lower compared to the annual average (71-75\%) over the last five years in Serbia and in the EU/EEA region [4,1]. However, extra-pulmonary TB $(35.3 \%)$ was almost 3 times more frequent than the country's annual 5 years average: $11-13 \%$. In contrast to the previous reports in the literature, in this outbreak females were more likely to be affected than males in this age group, although the difference was not statistically significant $[14,15]$.

Similar to the previously reported school/university outbreaks, classes were not equally affected $[16,17]$. The most affected classes, C10 and C3, had 2-fold higher risk of TB occurrence and $100 \%$ and $66 \%$ of the

Table 2. Independent risk factors for TB among students according to the multiple log-binomial regression analysis.

\begin{tabular}{llllc}
\hline Variable & RR & \multicolumn{1}{c}{$\mathbf{9 5 \%}$ Confidence interval } & p-value \\
\hline Previous TB disease in family & 5.29 & 1.63 & 17.12 & 0.005 \\
Spending time with TB friend in school* & 5.38 & 1.48 & 19.55 & 0.011 \\
Exposure to secondhand smoke & 3.37 & 1.11 & 10.29 & 0.033 \\
\hline
\end{tabular}

*At least cumulatively eight hours per week. 
cases were sputum smear positive, respectively. In comparison, there was only one extra-pulmonary $\mathrm{TB}$ (case No 7) in $\mathrm{C} 2$, which otherwise was not linked to any other cases. As presented in Figure 1, exposure to other known TB cases in school could explain the occurrence of the majority TB cases in this outbreak. As reported in previous TB outbreaks in schools and universities, the movement of the students between classes and potentially the classrooms' ventilation characteristics likely have contributed to the airborne transmission of the disease [16-18]. Although according to the national Regulations it is mandatory to report communicable diseases cases within 24 hours after diagnosis, in this outbreak there was a significant delay in reporting the first 4 cases and subsequent active case finding [19]. The initial phase of the large-scale active case finding was conducted after a 4-8-week delay following the diagnosis of the first cases (3 pulmonary TB and 1 extra-pulmonary case), targeting $84 \%$ of all students and $100 \%$ employees. In addition, active case finding covered all students and employees without differentiating a "close contacts" group who spent $\geq 8$ hours per week with a TB case at school as a priority group. Further, investigation of contacts by chest X-ray targeting only the clinically overt disease rather than LTBI as per the national guidelines, prevented the administration of prophylactic TB treatment. Several countries are currently using a twostep strategy (TST followed by IGRA) in outbreak investigations $[16,17,20]$. However, the investigation of close contacts with TST and/or Interferon Gamma Release Assays (IGRA) is not recommended by the Serbian national guidelines, even though Serbia is included among countries supporting the implementation of the WHO guidelines on the management of LTBI $[5,8]$. In low TB incidence countries, household or other close contacts of bacteriologically confirmed pulmonary TB cases should be systematically screened and treated for LTBI accordingly [5]. The prevalence of LTBI among close contacts can be as high as $51 \%$ and can be higher among adolescents $>15$ years and adults. In contrast to the results of previous studies, demographics and socioeconomic factors were not significantly associated with increased risk of TB in this outbreak. Nevertheless, the majority of these results refer to endemic/sporadic rather than epidemic cases [16,20,21]. Our results have not confirmed an increased risk of disease associated with alcohol consumption, smoking and hookah use. Other health related behaviors and factors such as regular daily food intake, regular daily sleeping pattern and self- perceptions of stressful situations/events have not been associated with increased risk of TB either.

In our study, although increased, the risk of developing TB was not significantly associated with comorbidities, which is in contrast to the results of previous studies focusing on non-endemic settings [22]. Generally, people at high risk of developing TB disease are those recently infected with TB (6-12 months after exposure), at specific age groups (highest in children $<$ 3 years' old, adolescents, young or very old adults), and those who are immunocompromised. Our study participants were third-grade high school students, with a very low frequency of co-morbidities except asthma and chronic bronchitis, the former being known to potentially increase susceptibility to TB infection due to the associated reduced local mucous-ciliary function of the alveolar macrophages and/or the long-term use of inhaled corticosteroids [22,23].

Secondhand smoking (SHS) was identified as a statistically significant risk factor associated with the development of TB. Recent studies confirm the correlation between the prevalence of tobacco use and tuberculosis [24]. Passive or active exposure to tobacco smoke is known to be significantly associated with TB infection and TB disease, independent of the effects of alcohol use, socioeconomic status and other factors [25]. Exposure to SHS is known to reduce the lung defense function increasing susceptibility to TB infection as well as decrease the treatment efficacy [26,27]. Exposure to SHS was also associated with delayed sputum smear conversion, persistent infectivity and relapse as well as increased risk of progression from LTBI to TB disease $[28,29]$.

Spending $\geq 8$ hours per week with a known TB case at school "TB friend" was identified as another independent factor associated with the development of $\mathrm{TB}$, in line with the previous literature. TB transmission is airborne through inhalation of infected nuclei. The risk of infection depends on the degree of exposure. People with pulmonary or laryngeal TB are most likely to transmit the bacteria as long as they are infectious (in the absence of effective treatment) to people they spend time with every day including family members, friends, coworkers and schoolmates "clusters in space and time" [30-32]. Early detection and immediate effective treatment can reduce the infectiousness and infectiousness duration of the TB cases. Reducing crowding conditions and improving the ventilation can also decrease the contact rate, although evidence is limited about the minimum standards of optimal ventilation in closed spaces for preventing $\mathrm{TB}$ transmission $[32,33]$. 
TB family history was also identified as an independent risk factor in our study, in line with results of previous studies. TB has always been considered a "disease of close contact", although nowadays transmission is more likely to happen outside the household in high-burden settings [33]. Therefore, some of the cases in this outbreak might have acquired the infection outside the school, for instance in their households, a hypothesis which has already been raised in the descriptive part of this study - Figure 1.

Although cases with the same TB genotype may be involved in the same chain of transmission, the presence of a genotype cluster in this outbreak cannot be ruled out given the absence of available historical data in the community and the country. Further, genotyping is considered an imperfect tool for confirming transmission between patients as 24-locus MIRU only characterizes a portion of the $M$. tuberculosis genome. It is, therefore, possible for 2 different strains to appear similar [32].

Novi Pazar has been a TB hot-spot city over the last half century $[4,8,9]$. Screening the household members and close contacts in congregated settings for LTBI and administration of preventive TB treatment, accordingly, remains an important prevention measure for halting TB transmission.

\section{Limitations}

Face to face administration of the questionnaire might have led to information bias, interfering with the information collected on the income status, smoking, alcohol consumption and hookah use, potentially related to social barriers and perception of stigma. We were not able to compare the MIRU genotyping results with genotyping profiles of other cases in Novi Pazar and Serbia since genetic analysis is not routinely performed. We did not perform an extensive social network investigation and analysis in other common places of exposure outside the school. Leisure and recreational settings were studied as transmission settings in previous TB outbreaks [33].

Despite its limitations, our study provides evidence on the risk factors associated with a TB outbreak in a hot TB spot area in a low incidence country. The analytical study results are in agreement with the findings of the descriptive study. Delayed diagnosis and delayed reporting of the first cases resulted in delayed implementation of the active case finding. Not prioritizing "close contacts" in the active case finding and not identifying LTBI cases had potentially favored the occurrence of this high school outbreak. Further, our results point to a dual transmission path, inside and outside the school compatible with the known ongoing community-based TB transmission.

\section{Conclusions and Recommendations}

Delayed diagnosis and reporting resulted in delayed initiation of the contact investigation and nonidentification of latent TB cases probably favored the occurrence of this outbreak in a low incidence country.

There is a need to increase awareness among public health professionals about the specificities of the close contact identification and management, and their potential impact on the TB epidemiology in Novi Pazar. There is also a need to increase awareness of the community and general public on the early suspicion, prevention and management of potential TB cases. It is important to revise existing guidelines on the identification and management of LTBI and update national TB prevention and control strategy using available scientific evidence, international expertise and national data with an emphasis on the inter-sectoral collaboration, human resources development and adapted previsions for the hot-spot areas.

\section{Acknowledgements}

We thank Dr Hedija Alibasic, Head of TB Unit of General Hospital of Novi Pazar and Dr Safet Ganic from the District Public Health Institute for their valuable assistance during this investigation, as well as Professor Branislava Savic, Head of National Reference Laboratory for Mycobacteria for her collaboration with SNRL in Borstel, Germany. This outbreak investigation was implemented within the Mediterranean Program for Intervention Epidemiology Training- MediPIET, and supported by Ministry of Education, Science and Technological Development of the Republic of Serbia as well (grants No. 175042 and 175087).

\section{Author Contributions}

MS, DP, NM and AG designed and wrote the manuscript, DP and AG analyzed data, LS, UR and SS helped with the paper. MS, DP, NM, DJ, VV, GS and AG made critical revisions. All authors read and approved the final manuscript.

\section{Ethical considerations}

This investigation was approved by the Ethic Committee of the Institute of Public Health of Serbia. Informed consent was given by participants at the beginning of the interview. For participants younger than 18 years, consent of the parents was obtained.

\section{References}

1. European Centre for Disease Prevention and Control (2016) Tuberculosis surveillance and monitoring in Europe 2016. Stockholm: ECDC report. Available: https://ecdc.europa.eu/sites/portal/files/media/en/publications/ 
Publications/ecdc-tuberculosis-surveillance-monitoringEurope-2016.pdf. Accessed: 12 September 2018.

2. Houben RM, Dodd PJ (2016) The global burden of latent tuberculosis infection: A re-estimation using mathematical modelling. PLoS Med 13: e1002152.

3. O'Garra A, Redford PS, McNab FW, Bloom CI, Wilkinson RJ, Berry MP (2013) The immune response in tuberculosis. Annu Rev Immunol 31: 475-527.

4. Public Health Institute of Serbia (2017) Report on communucable diseases in the Republic of Serbia for 2016. Available:

http://www.batut.org.rs/download/izvestaji/Zarazne\%20bolest i\%20godisnji\%20izvestaj\%202016.pdf Accessed: 12 September 2018. [Article in Serbian]

5. World Health Organization (2018) Latent tuberculosis infection: updated and consolidated guidelines for programmatic management. Geneva: WHO. Available: https://apps.who.int/iris/bitstream/handle/10665/260233/9789 241550239-

eng.pdf;jsessionid=853B6E0F7F97CF918D345928966C7415 ?sequence $=1$ Accessed: 14 September 2018.

6. Ministry of Health of the Republic of Serbia (2018) Rulebook on immunization and medicinal protection (Official Gazzette of the Republic of Serbia 88/2017, 11/2018 and 14/2018) Available:

https://www.paragraf.rs/propisi/pravilnik_o_imunizaciji_i_na cinu_zastite_lekovima.html Accessed: 14 September 2018. [Document in Serbian]

7. Curcic R, Sagic L, Kuruc V (2011) Guidelines for contact tracing, latent tuberculosis infection and chemioprophilaxis. Belgrade: Ministry of Health of the Republic of Serbia 10 p. [Article in Serbian]

8. Statistical Office of the Republic of Serbia (2017) Statistic yearbook of the Republic of Serbia. Available: http://publikacije.stat.gov.rs/G2017/PdfE/G20172022.pdf Accessed: 18 September 2018. [Article in Serbian].

9. Radosavljevic Asic G, Rebic P, Kuruc V (2009) Methodological guidelines for tuberculosis prevention and control. Belgrade: Ministry of Health of the Republic of Serbia. Available:

http://www.batut.org.rs/download/izdvajamo/tuberkuloza/Rev idirano $\% 20$ Strucno-

metodolosko\%20uputstvo\%20sprecavanje \%20suzbijanje $\% 20$ TB\%20RS\%202009.pdf.Accessed: 18 September 2018. [Article in Serbian].

10. Russell S (2004) The economic burden of illness for households in developing countries: a review of studies focusing on malaria, tuberculosis, and human immunodeficiency virus/acquired immunodeficiency syndrome. Am J Trop Med Hyg 71 Suppl 2: 147-155.

11. Centers for Disease Control and Prevention (2014) Tuberculosis outbreak detection and response. Atlanta: CDC. Available:

https://www.cdc.gov/tb/education/ssmodules/pdfs/Module9.p df. Accessed: 18 September 2018

12. Vukovic DS, Nagorni-Obradovic LM (2011) Knowledge and awareness of tuberculosis among Roma population in Belgrade: a qualitative study. BMC Infect Dis 11: 284.

13. The European Commission (2012) Commission Implementing Decision of 8 August 2012 amending Decision 2002/253/EC laying down case definitions for reporting communicable diseases to the Community network under Decision No 2119/98/EC of the European Parliament and of the Council (notified under document C (2012) 5538). Official Journal of the European Union L 262, 27.9. 2012, p. 1-57. Brussels. Belgium. EC. Available: https://eur-lex.europa.eu/legalcontent/EN/TXT/?uri=CELEX\%3A32012D0506 Accessed: 19 September 2018

14. Holmes CB, Hausler H, Nunn P (1998) A review of sex differences in the epidemiology of tuberculosis. Int $\mathrm{J}$ Tuberc Lung Dis 2: 96-104.

15. Li CY, Chen HC, Cheng HY, Chian CF, Chang FY, Chen HI, $\mathrm{Ku} \mathrm{CH}$, Lin JC (2015) Role of QuantiFERON-TB-Gold In Tube assay for active and latent tuberculosis infection in investigation of tuberculosis outbreak in a university. J Microbiol Immunol Infect 48: 26326-8.

16. Churchyard G, Kim P, Sarita Shah N, Rustomjee R, Gandhi N, Mathema B, Dowdy D, Kasmar A, Cardenas V (2017) Overview of knowledge about tuberculosis transmission. J Infect Dis Suppl 6: 216.

17. Li Y, Leung GM, Tang JW, Yang X, Chao CY, Lin JZ, Lu JW, Nielsen PV, Niu J, Qian H, Sleigh AC, Su HJ, Sundell J, Wong TW, Yuen PL (2007) Role of ventilation in airborne transmission of infectious agents in the built environment $-\mathrm{a}$ multidisciplinary systematic review. Indoor Air 17: 2-18.

18. Law on Population Protection against Communicable Diseases. Official Gazzette of the Republic of Serbia 15/2016. Ministry of Health of the Republic of Serbia. Belgrade. Available:

https://www.paragraf.rs/propisi/zakon_o_zastiti_stanovnistva _od_zaraznih_bolesti.html. Accessed 20 September 2018. [Document in Serbian]

19. Camden TL, Maruffo D, Santos N, Nava JJ, Alcantara C (2015) Investigation of Tuberculosis in a High School - San Antonio, Texas, 2012. Morb Mortal Wkly Rep 64: 825-856.

20. Khaled N (2010) Management of tuberculosis: a guide to essentials of good practice. Paris: International Union against Tuberculosis and Lung Disease. Available: https://www.theunion.org/what-we-

do/publications/technical/english/pub_orange-guide_eng.pdf. Accessed: 20 September 2018.

21. Souza de Lima D, Nunes VCL, Ogusku MM, Sadahiro A, Pontillo A, Alencar BC (2017) Polymorphisms in SIGLEC1 contribute to susceptibility to pulmonary active tuberculosis possibly through the modulation of IL-1ß. Infect Genet Evol 28: 313-317.

22. Kim JH, Park JS, Kim KH, Jeong HC, Kim EK, Lee JH (2013) Inhaled corticosteroid is associated with an increased risk of tuberculosis in patients with chronic obstructive pulmonary disease. Chest 143: 1018-1024.

23. Harling G, Lima Neto AS, Sousa GS, Machado MMT, Castro MC (2017) Determinants of tuberculosis transmission and treatment abandonment in Fortaleza, Brazil. BMC Public Health 25: 507-508.

24. Chan ED, Kinney WH, Honda JR, Bishwakarma R, Gangavelli A, Mya J, Bai X, Ordway DJ (2014) Tobacco exposure and susceptibility to tuberculosis: is there a smoking gun? Tuberculosis 94: 544-550.

25. World Health Organization (2007) A WHO/The Union Monograph on TB and Tobacco Control: joining efforts to control two related global epidemics. Geneva: World Health Organization $33 \mathrm{p}$.

26. Khan AH, Israr M, Khan A, Aftab RA, Khan TM (2015) Smoking on treatment outcomes among tuberculosis patients. Am J Med Sci 349: 505-509. 
27. M Pai, A Mohan, K Dheda, CC Leung, WW Yew, DJ Christopher, SK Sharma (2007) Lethal interaction: the colliding epidemics of tobacco and tuberculosis. Expert Rev Anti Infect Ther 5: 385-391.

28. Dogar OF, Pillai N, Safdar N, Shah SK, Zahid R, Siddiqi K (2015) Second-hand smoke and the risk of tuberculosis: a systematic review and a meta-analysis. Epidemiol Infect 143: 3158-3172.

29. World Health Organization (2012) Recommendations for investigating contacts of persons with infectious tuberculosis in low- and middle-income countries. Geneva: World Health Organization.

Available: https://apps.who.int/iris/bitstream/handle/10665/77741/97892 41504492_eng.pdf? sequence $=1$. Accessed: 24 September 2018.

30. World Health Organization (2015) Guidelines on the management of latent tuberculosis infection. Geneva: World Health Organization. Available: https://apps.who.int/iris/bitstream/handle/10665/136471/9789 241548908_eng.pdf?sequence $=1$. Accessed: 24 September 2018.

31. Kim Y, Kim BK, Choi HJ, Ryu SW, Kim ES, Chang YS, Kim HJ, Cha JH, Kim JH, Shin C, Lee SH (2017) Lessons learned from continued TB outbreaks in a high school. PLoS ONE 12: e0188076.

32. Surie D, Fane O, Finlay A, Ogopotse M, Tobias JL, Click ES, Modongo C, Zetola NM, Moonan PK, Oeltmann JE; Kopanyo Study Group. (2017) Molecular, spatial, and field epidemiology suggesting TB transmission in community, nothospital, Gaborone, Botswana. Emerg Infect Dis 3: 487490.

33. Godoy $\mathrm{P}$ Alsedà $\mathrm{M}$, Falguera $\mathrm{M}$, Puig $\mathrm{T}$ Bach $\mathrm{P}$, Monrabà $\mathrm{M}$ Manonelles A (2017) A highly transmissible tuberculosis outbreak: the importance of bars. Epidemiol Infect 145: 34973504.

\section{Corresponding author}

Maja Stosic

Department of HIV, hepatitis, STDs and TB

Public Health Institute of Serbia "Dr Milan Jovanovic Batut"

Belgrade, Serbia, Dr Subotica 5, 11000 Belgrade

Phone: +381641278571

Email: maja_stosic@batut.org.rs

Conflict of interests: No conflict of interests is declared. 